\title{
MicroRNA-198 suppresses tumour growth and metastasis in oral squamous cell carcinoma by targeting CDK4
}

\author{
YUANYUAN KANG, YING ZHANG and YAN SUN
}

\begin{abstract}
Department of Emergency and Oral Medicine, School and Hospital of Stomatology, China Medical University, Liaoning Provincial Key Laboratory of Oral Diseases, Shenyang, Liaoning 110002, P.R. China
\end{abstract}

Received January 4, 2021; Accepted April 14, 2021

DOI: $10.3892 /$ ijo.2021.5219

\begin{abstract}
MicroRNAs (miRNAs/miR) often contribute to the progression of oral squamous cell carcinoma (OSCC) via the regulation of mRNA. The present study aimed to investigate the role of miR-198 in OSCC pathogenesis and explore the underlying mechanism. Reverse transcription-quantitative (RT-q)PCR was performed to determine miR-198 expression in OSCC tissues and cell lines, and univariate and multivariate analyses were applied to evaluate the survival of patients with OSCC. The effects of miR-198 on OSCC cell lines were studied in vitro and in vivo. A set of epithelial-mesenchymal transition (EMT) markers were detected to determine whether miR-198 was involved in EMT. Lastly, using luciferase assays, a novel target of miR-198 was identified and the effect of the new target gene of miR-198 on cell proliferation and invasion was also studied. It was identified that miR-198 expression was decreased in OSCC tissues and cell lines, and low expression of miR-198 was associated with poor overall survival and disease-free survival. Overexpression of miR-198 appeared to significantly inhibit the proliferation, invasion and EMT of OSCC cells. Moreover, the luciferase assay results showed that miR-198 interacted with cyclin-dependent kinase 4 (CDK4) by directly targeting the miRNA-binding site in the CDK4 sequence, and RT-qPCR results showed that CDK4 expression was increased in OSCC tissues and cell lines. In addition, transfection of small interfering RNA against CDK4 in OSCC cells showed similar inhibitory effects on cell proliferation, invasion and EMT, whereas CDK4 overexpression in OSCC cells partially reversed the inhibitory effects of the miR-198 mimic. The present results indicated that miR-198 suppressed OSCC tumour growth and metastasis by directly targeting
\end{abstract}

Correspondence to: Dr Yuanyuan Kang, Department of Emergency and Oral Medicine, School and Hospital of Stomatology, China Medical University, Liaoning Provincial Key Laboratory of Oral Diseases, 117 North Nanjing Street, Heping, Shenyang, Liaoning 110002, P.R. China

E-mail:20082068@cmu.edu.cn

Key words: microRNA-198, oral squamous cell carcinoma, proliferation, invasion, epithelial-mesenchymal transition
CDK4 expression. Thus, miR-198 may be a potential therapeutic target in the treatment of OSCC.

\section{Introduction}

Oral squamous cell carcinoma (OSCC) is a destructive and lethal malignant tumour that accounts for $>90 \%$ of all oral cancers and is the sixth most common type of cancer worldwide (1). Due to its anatomical location, OSCC affects patients seriously, and most of them have poor prognosis. Risk factors for OSCC include alcohol consumption, tobacco smoking and adverse irritation of the oral mucosa $(2,3)$. Although great progress has been made in the treatment of OSCC, the 5-year survival rate has not improved much over the past two decades (4,5). Therefore, further understanding of the pathogenesis of OSCC may help to predict cancer progression and provide novel molecular targets for cancer therapy.

MicroRNAs (miRNAs/miRs) belong to an endogenous class of small non-coding RNAs that function through inhibiting the translation levels of the target mRNAs $(6,7)$. Accumulating evidence has shown that miRNAs regulate cell proliferation and apoptosis, and play key roles in OSCC tumorigenesis, including miR-375, miR-139-5p, miR-155 and miR-21 (8-11). To date, downregulation of miR-198 has been found in various malignant tumours, including breast cancer, lung cancer and hepatocellular carcinoma (12-14). Furthermore, miR-198 is an independent prognostic factor in gastric cancer and glioma (15). However, the role of miR-198 in OSCC has not been fully investigated.

Epithelial-mesenchymal transition (EMT) is a biological process in which epithelial cells transform into cells with a mesenchymal phenotype through specific procedures. EMT plays an important role in cancer metastasis. In the present study, the expression of miR-198 in OSCC was examined. Furthermore, the effects of miR-198 on the proliferation, invasion and EMT of OSCC cells was analysed and the associated underlying mechanisms were explored. These findings suggested that miR-198 acts as a potential biomarker for OSCC.

\section{Materials and methods}

Tissue samples. A total of 80 OSCC tissues and adjacent non-tumour tissues from patients at the School and Hospital 
of Stomatology, China Medical University (Shenyang, China) between January 2013 and January 2015 were selected. Patients with malignancies in other organs and those who had received any anti-cancer therapy were excluded. Clinical data including age, sex, primary tumour site, differentiation, tumour node metastasis (TNM) classification and recurrence were obtained from pathological and clinical records. The ethics committee of the School and Hospital of Stomatology, China Medical University approved the present study and written informed consent was obtained from patients providing tissue specimens.

Cell culture. Human OSCC cell lines (Cal-27, SCC-9 and SCC-25) and human keratinocytes cell line (HaCaT cells) were purchased from the American Type Culture Collection, and were maintained in Dulbecco's modified Eagle's medium (DMEM) supplemented with $10 \%$ foetal bovine serum (FBS) and a 1\% penicillin-streptomycin solution in a humidified atmosphere containing $5 \% \mathrm{CO}_{2}$ at $37^{\circ} \mathrm{C}$. The cell culture medium and FBS were purchased from Gibco (Thermo Fisher Scientific, Inc.). The HaCaT cell line was originated from normal skin tissue. The normal oral mucosal epithelial cell line is not widely available, and the structure of the skin is very similar to the structure of the oral mucosa, so HaCaT cells were used as the control, as previously described $(16,17)$. The $\mathrm{HaCaT}$ cell line was authenticated by STR sequencing.

Cell transfection. miR-198 mimics, small interfering RNA (siRNA/si-) targeting cyclin-dependent kinase 4 (CDK4) and negative controls (NCs) were designed and synthesised by Shanghai GenePharma Co., Ltd. Cells (Cal-27 and SCC-9) were seeded into 96-well plates in antibiotic-free growth medium at a density of $4 \times 10^{3}$ cells/well. miR-198 mimics $(100 \mathrm{nmol} / \mu \mathrm{l}$; 5'-GGUCCAGAGGGGAGAUAGGUUC-3') and the control (100 nmol $/ \mu 1 ; 5 '$-UUCUCCGAACGUGUCACGUAAU-3') were transfected when the cells reached $70-80 \%$ confluence. si-CDK4 $(80 \mathrm{nmol} / \mu \mathrm{l}$; sense, 5 '-CAGUUCGUGAGGUGC UUUAC-3' and antisense, 5'-GUAA AGCCACCUCACGAAC UG-3') and si-Ctrl (80 nmol $/ \mu 1$; sense, 5'-UUCUCCGAGCGU GUCACGUTT-3' and antisense, 5'-ACGUGACACGUUCGG AGAATT-3') were transfected using Lipofectamine ${ }^{\circledR} 3000$ (Invitrogen; Thermo Fisher Scientific, Inc.) when cells reached $30-40 \%$ confluence, in accordance with the manufacturer's protocol. By inserting CDK4 cDNA into the pcDNA3.1 vector (Shanghai GenePharma Co., Ltd.), the CDK4 overexpression plasmid (pcDNA-CDK4) was generated and its sequence was confirmed by Shanghai GenePharma Co., Ltd. An empty pcDNA3.1 vector was used as the NC. Using Lipofectamine 3000 , pcDNA-CDK4 $(500 \mathrm{ng} / \mu \mathrm{l})$ was transfected into cells. After incubation at $37^{\circ} \mathrm{C}$ for $6 \mathrm{~h}$, the culture medium was changed. After transfection for $48 \mathrm{~h}$, the subsequent experimentation was carried out. Transfection efficiency was analysed via reverse transcription-quantitative PCR (RT-qPCR).

$R T-q P C R$. Total RNA was extracted from frozen tissues and Cal-27, SCC-9 and HaCat cells using TRIzol ${ }^{\circledR}$ (Takara Biotechnology Co., Ltd.) according to the manufacturer's protocol. Using standard spectrophotometric methods, RNA concentration was quantified and its purity was determined.
To examine miR-198 expression, RNA $(1 \mu \mathrm{g})$ was reverse transcribed using Hairpin-it ${ }^{\mathrm{TM}}$ miRNA and a U6 snRNA Normalisation Kit (Shanghai GenePharma Co., Ltd.). The RT reaction system contained the following: $4 \mu 15 \mathrm{X}$ MMLV RT buffer, $0.75 \mu 1$ dNTP, $1.2 \mu 1$ miRNA and U6 snRNA RT primer mix, 0.2 $\mu 1 \mathrm{MML}$ reverse transcriptase $(200 \mathrm{U} / \mu 1)^{2}$, $1 \mu \mathrm{g}$ RNA and RNase-free $\mathrm{H}_{2} \mathrm{O}$, which added up to $20 \mu 1$. The following conditions were employed for RT: $25^{\circ} \mathrm{C}$ for $30 \mathrm{~min}, 42^{\circ} \mathrm{C}$ for $30 \mathrm{~min}$ and $85^{\circ} \mathrm{C}$ for $5 \mathrm{~min}$. The qPCR reaction system contained: $10 \mu \mathrm{l} 2 \mathrm{X}$ Real-time PCR Master Mix, $0.4 \mu 1$ miRNA and U6 snRNA specific primer set $(10 \mu \mathrm{M})^{1}, 0.4 \mu 1$ ROX reference dye (50X) $)^{3}, 0.2 \mu 1$ Taq DNA polymerase $(5 \mathrm{U} / \mu \mathrm{l}), 2 \mu \mathrm{l}$ miRNA RT product and sterilised $\mathrm{H}_{2} \mathrm{O}$, which added up to $20 \mu 1$. The thermocycling conditions were as follows: $95^{\circ} \mathrm{C}$ for $3 \mathrm{~min}, 95^{\circ} \mathrm{C}$ for $12 \mathrm{sec}$ and $62^{\circ} \mathrm{C}$ for $40 \mathrm{sec}$. Gene expression was normalised to U6 expression, which was used as an internal control, and the relative expression level was calculated using the $2^{-\Delta \Delta \mathrm{Cq}}$ method (18). The patients were divided into two groups based on the median level of miR-198 expression: High expression and low expression.

To determine the expression of E-cadherin, $\mathrm{N}$-cadherin, vimentin, MMP-2, MMP-9 and CDK4, cDNA served as the template for PCR amplification using a cDNA synthesis kit (Takara Biotechnology Co., Ltd.), according to the manufacturer's protocol. The RT reaction system contained the following: $4 \mu 1$ 5X PrimeScript RT Master Mix, $1 \mu \mathrm{g}$ RNA and RNase-free $\mathrm{H}_{2} \mathrm{O}$, which added up to $20 \mu \mathrm{l}$. The following conditions were employed for RT: $37^{\circ} \mathrm{C}$ for $15 \mathrm{~min}$ and $85^{\circ} \mathrm{C}$ for 5 min. qPCR was conducted using SYBR Premix Ex Taq II kit (Takara Biotechnology Co., Ltd.) with the following reaction system: $10 \mu \mathrm{l}$ SYBR Premix Ex Taq II, $1 \mu \mathrm{l}$ cDNA, $0.5 \mu \mathrm{l}$ forward primer, $0.5 \mu 1$ reverse primer and $8 \mu 1$ sterile water. The thermocycling conditions were as follows: $95^{\circ} \mathrm{C}$ for $1 \mathrm{~min}$, $94^{\circ} \mathrm{C}$ for $30 \mathrm{sec}, 58^{\circ} \mathrm{C}$ for $30 \mathrm{sec}$ and $72^{\circ} \mathrm{C}$ for $10 \mathrm{sec}$. Primers were designed and synthesised by Takara Biotechnology Co., Ltd. Gene expression was normalised to GAPDH expression, which was used as an internal control, and the relative expression level was calculated using the $2^{-\Delta \Delta C q}$ method.

Western blotting. Total protein from Cal-27 and SCC-9 cells were extracted using RIPA lysis buffer (CoWin Biosciences) containing PMSF $(1 \mathrm{mM})$ and the concentration was determined using the bicinchoninic acid method. Subsequently, $50 \mu \mathrm{g}$ total protein was separated via SDS-PAGE on a $10 \%$ gel, and subsequently separated proteins were transferred onto PVDF membranes (Sigma-Aldrich; Merck KGaA). Following blocking for $1 \mathrm{~h}$ with $5 \%$ non-fat milk at room temperature, the membranes were incubated with primary antibodies against E-cadherin (cat. no. 3195; 1:1,000; Cell Signaling Technology, Inc.), N-cadherin (cat. no. 13116; 1:500; Cell Signaling Technology, Inc.), vimentin (cat. no. 5741; 1:1,000; Cell Signaling Technology, Inc.), MMP-2 (cat. no. 40994; 1:1,000; Cell Signaling Technology, Inc.), MMP-9 (cat. no. 13667; 1:1,000; Cell Signaling Technology, Inc.), CDK4 (cat. no. 12790; 1:1,000; Cell Signaling Technology, Inc.) and GAPDH (cat. no. sc-47724; 1:5,000; Santa Cruz Biotechnology, Inc.) overnight at $4^{\circ} \mathrm{C}$. The membranes were washed and then incubated with the secondary antibodies (cat. nos. sc-2357 and sc-2005; 1:5,000; Santa Cruz 
Table I. Univariate and multivariate Cox proportional hazards model for OS and DFS in patients with oral squamous cell carcinoma.

\begin{tabular}{|c|c|c|c|c|c|c|}
\hline \multicolumn{7}{|l|}{ A, OS } \\
\hline \multirow[b]{2}{*}{ Variables } & \multicolumn{3}{|c|}{ Univariate } & \multicolumn{3}{|c|}{ Multivariate } \\
\hline & HR & $95 \% \mathrm{CI}$ & P-value & HR & $95 \% \mathrm{CI}$ & P-value \\
\hline Sex (male vs. female) & 1.441 & $0.412-2.113$ & 0.549 & & & \\
\hline Age, years ( $\leq 55$ vs. $>55)$ & 1.559 & $0.712-2.176$ & 0.432 & & & \\
\hline Differentiation (well/moderate vs. poor) & 3.554 & $0.558-3.569$ & $0.030^{\mathrm{a}}$ & & & \\
\hline Tumour size, cm ( $\leq 5$ vs. $>5$ ) & 1.023 & $0.990-1.997$ & 0.151 & & & \\
\hline TNM stage (II+III vs. I) & 2.814 & $0.998-3.698$ & $0.039^{\mathrm{a}}$ & 2.612 & $1.122-3.006$ & $0.043^{\mathrm{a}}$ \\
\hline miR-198 expression (high vs. low) & 3.996 & $1.345-5.885$ & $0.025^{\mathrm{a}}$ & 3.221 & $1.443-4.113$ & $0.033^{\mathrm{a}}$ \\
\hline Tobacco usage (yes vs. no) & 1.630 & $0.782-2.432$ & 0.321 & & & \\
\hline
\end{tabular}

$\mathrm{B}, \mathrm{DFS}$

\begin{tabular}{|c|c|c|c|c|c|c|}
\hline \multirow[b]{2}{*}{ Variables } & \multicolumn{3}{|c|}{ Univariate } & \multicolumn{3}{|c|}{ Multivariate } \\
\hline & $\mathrm{HR}$ & $95 \% \mathrm{CI}$ & $\mathrm{P}$-value & HR & $95 \% \mathrm{CI}$ & P-value \\
\hline Sex (male vs. female) & 1.224 & $0.712-2.114$ & 0.821 & & & \\
\hline Age, years ( $\leq 55$ vs. $>55)$ & 1.421 & $0.674-2.032$ & 0.726 & & & \\
\hline Differentiation (well/moderate vs. poor) & 3.002 & $1.092-4.012$ & $0.034^{\mathrm{a}}$ & & & \\
\hline Tumour size, cm ( $\leq 5$ vs. $>5$ ) & 1.123 & $0.598-2.912$ & 0.915 & & & \\
\hline TNM stage (II+III vs. I) & 3.443 & $1.012-4.098$ & $0.031^{\mathrm{a}}$ & 3.123 & $0.114-3.234$ & $0.033^{\mathrm{a}}$ \\
\hline miR-198 expression (high vs. low) & 3.609 & $1.123-5.334$ & $0.022^{\mathrm{a}}$ & 3.567 & $1.379-4.453$ & $0.027^{\mathrm{a}}$ \\
\hline Tobacco usage (yes vs. no) & 1.768 & $0.543-4.119$ & 0.564 & & & \\
\hline
\end{tabular}

OS, overall survival; DFS, disease-free survival; TNM, tumour node metastasis; miR, microRNA. ${ }^{\mathrm{P}}<0.05$.

Biotechnology, Inc.) for $2 \mathrm{~h}$ at room temperature. The blots were visualised via ECL (Pierce; Thermo Fisher Scientific, Inc.). ImageJ software (version 1.48; National Institutes of Health) was used for densitometry.

Bioinformatics analysis. The CDK4 expression data for OSCC was obtained from the Gene Expression Profiling Interactive Analysis (GEPIA) online database (http://gepia.cancer-pku.cn/). Tumour and normal samples in the GEPIA database were derived from The Cancer Genome Atlas (TCGA, https://tcga-data.nci. nih.gov/tcga/) and the Genotype-Tissue Expression (GTEx, https://www.gtexportal.org/home/) projects.

3-(4,5-dimethylthiazol-2-yl)-5-(3-carboxymethoxyphenyl)-2(4-sulfophenyl)-2H-tetrazolium (MTS) assay. OSCC Cal-27 and SCC-9 cells were transfected and seeded on 96-well plates at a density of $2 \times 10^{3}$ cells/well. After culture for $24,48,72$ or $96 \mathrm{~h}$, cell proliferation was tested via an MTS assay (Abcam), according to the manufacturer's protocol. The absorbance of each well was measured at $570 \mathrm{~nm}$ on a microplate reader.

Colony formation assay. OSCC Cal-27 and SCC-9 cells were transfected and seeded on 6-well plates at a density of $1 \times 10^{3}$ cells/well and cultured for 7 days. The medium was removed and cells were washed with PBS twice, fixed in $100 \%$ methanol $(1 \mathrm{ml})$ for $10 \mathrm{~min}$ and stained with $10 \%$ crystal violet solution for $20 \mathrm{~min}$ at room temperature, the colonies (defined as $>10$ cells) were counted and photographed.

Flow cytometry analysis. OSCC Cal-27 and SCC-9 cells were transfected and seeded on 6-well plates at a density of $4 \times 10^{5}$ cells/well and cultured for $48 \mathrm{~h}$. According to the manufacturer's protocols, cells were incubated with Annexin V-Fluorescein Isothiocyanate/Propidium Iodide Apoptosis Detection kit (Dojindo Molecular Technologies, Inc.) in the dark. The results were analysed using a BD FACSVerse $^{\mathrm{TM}}$ flow cytometer (BD Biosciences) equipped with the FlowJo version 10 software (FlowJo LLC). Early and late apoptosis was assessed.

Transwell assay. OSCC Cal-27 and SCC-9 cells were transfected, resuspended in serum-free DMEM, and plated onto the upper chamber of the Transwell insert (Corning, Inc.) at a density of $5 \times 10^{4}$ cells/well. DMEM containing $10 \%$ FBS $(500 \mu \mathrm{l})$ was added into the lower chamber to act as a chemoattractant. For the invasion experiments, Transwell chambers precoated with Matrigel (Corning, Inc.) at $4^{\circ} \mathrm{C}$ for $3 \mathrm{~h}$. Cells in the Transwell plates were cultured for $48 \mathrm{~h}$ at $37^{\circ} \mathrm{C}$ with $5 \% \mathrm{CO}_{2}$. The adherent cells on the upper surface of the insert membrane were removed using cotton tips. Cells that migrated 
A

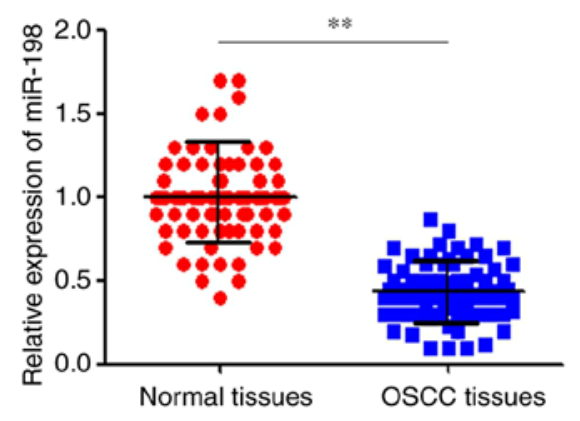

B

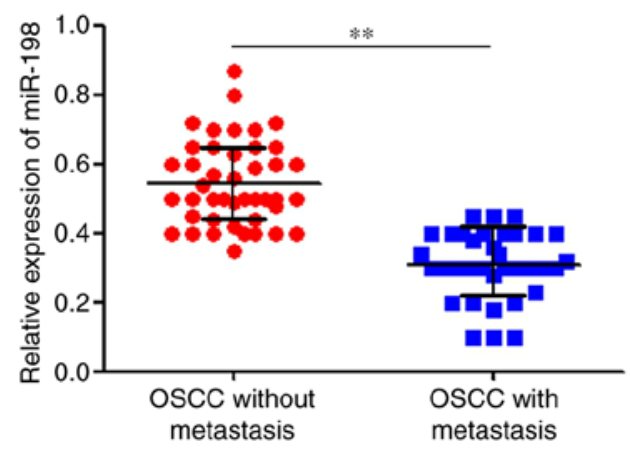

E
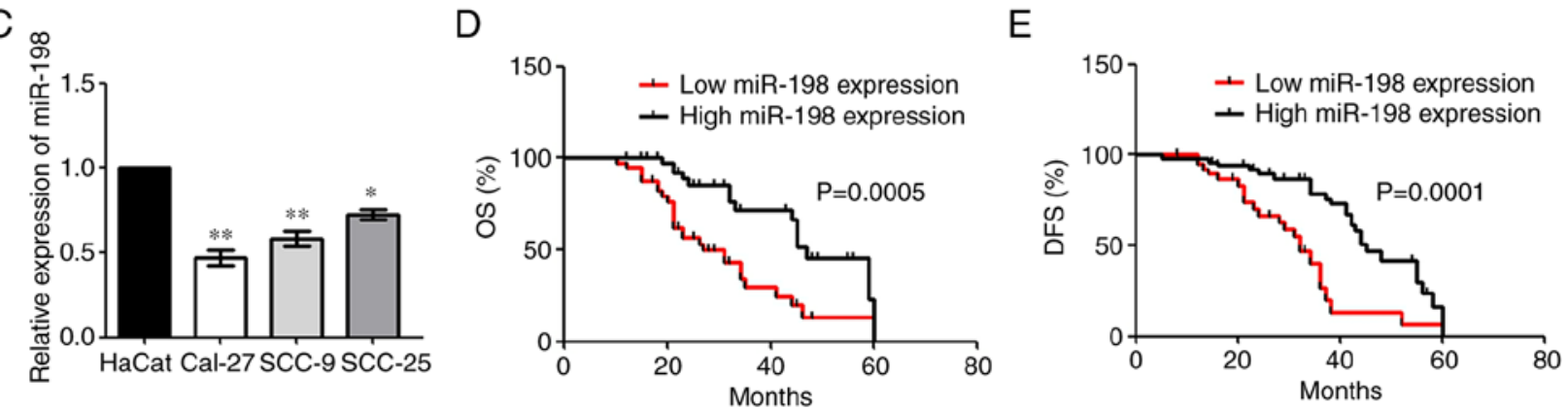

Figure 1. miR-198 expression in OSCC. (A) RT-qPCR analysis of miR-198 expression between OSCC tissues and normal tissues. (B) RT-qPCR analysis of miR-198 expression between patients with OSCC with and without metastasis. ${ }^{* *} \mathrm{P}<0.01$. (C) RT-qPCR analysis of miR-198 expression between the OSCC and HaCat cell lines. The Kaplan-Meier method was used to compare the (D) OS and (E) DFS rates based on the miR-198 expression. ${ }^{*} \mathrm{P}<0.05$, ${ }^{* *} \mathrm{P}<0.01 \mathrm{vs}$. HaCat cells. miR, microRNA; OSCC, oral squamous cell carcinoma; RT-qPCR, reverse transcription-quantitative PCR; OS, overall survival; DFS, disease-free survival.

into the lower chamber were stained with $10 \%$ crystal violet for 20 min at room temperature and quantitated by counting in five different areas under a light microscope.

Enzyme-linked immunosorbent assay (ELISA). According to a previous study (19), the OSCC Cal-27 and SCC-9 cell culture supernatant was collected after treatment. Using ELISA kits (cat. nos. MMP200 and DMP900; R\&D Systems, Inc.) the concentrations of MMP-2 and MMP-9 were measured, according to the manufacturer's protocol.

Dual-luciferase reporter assays. The potential binding sites of miR-198 and 3'-untranslated region (UTR) of CDK4 were predicted by TargetScan 7.1 (www.targetscan.org/vert_71). miR-198 mimics, miR NC and CDK4-3'UTR mutant (CDK4-MUT) and CDK4-3'UTR wild-type (CDK4-WT) plasmids were constructed by Shanghai GenePharma Co., Ltd. OSCC Cal-27 and SCC-9 cells were seeded on 6-well plates at a density of $3 \times 10^{4}$ cells/well. After $24 \mathrm{~h}$, miR-198 mimics (5'-GGUCCAGAGGGGAGAUAGGUUC-3') and miR NC (5'-UUCUCCGAACGUGUCACGUAAU-3') were co-transfected with CDK4-MUT or -WT plasmids into OSCC cells using Lipofectamine 3000. After incubation for $48 \mathrm{~h}$, according to the manufacturer's protocol, a Dual-Luciferase Reporter Assay System kit (Promega Corporation) was used. The relative luciferase activity was determined by normalisation with Renilla luciferase activity.

In vivo assays. A total of 24 male BALB/c nude mice (age, 4-6 weeks; weight, 20-25 g) were purchased from Beijing Vital River Laboratory Animal Technology Co., Ltd., (Charles
River Laboratories). All animals were raised at $22-26^{\circ} \mathrm{C}$, $40-70 \%$ relative humidity and a $12 \mathrm{~h}$ light/dark cycle. The animals were provided with water and food freely. All animals were randomly divided into two groups (experimental and control groups, 12 mice/group) and maintained in a specific pathogen-free environment. For the xenograft experiment, Cal-27 cells transfected with miR-198 mimics and miR-NC were detached and resuspended in serum-free medium. Subsequently, Cal-27 cells $\left(1 \mathrm{ml} ; 1 \times 10^{7}\right.$ cells $\left./ \mathrm{ml}\right)$ were implanted subcutaneously in the flanks of BALB/c nude mice (20). The tumour size was checked regularly at the indicated time points. The tumour-bearing mice were sacrificed 6 weeks after the operation by cervical dislocation and tumour weights were measured. The maximum tumour diameter was $13 \mathrm{~mm}$, and volume was $1,100 \mathrm{~mm}^{3}$. All animal studies were conducted at the Animal Center of China Medical University (Shenyang, China) according to the protocols approved by the animal ethics committee (Experimental animal welfare and ethics committee of China Medical University, approval no. CMU2019182).

Statistical analysis. All statistical analysis was performed using SPSS 21.0 software (IBM Corp.). Data are represented as the mean \pm standard deviation based on at least three repeats. Comparisons between tumour and adjacent normal tissue expression were performed using a paired Student's t-test. For cell line experiments involving two groups, an unpaired t-test was conducted. One-way ANOVA followed by Tukey's post hoc test was performed to compare the differences between multiple groups. Using the Kaplan-Meier method and the log-rank test, survival curves were plotted and the overall 

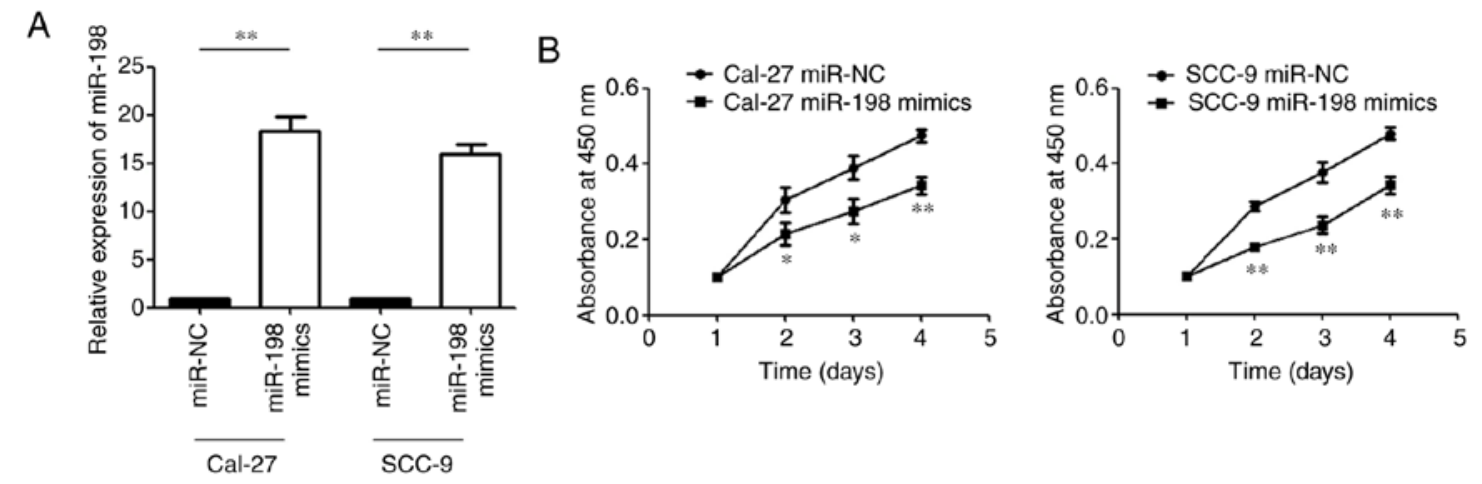

C
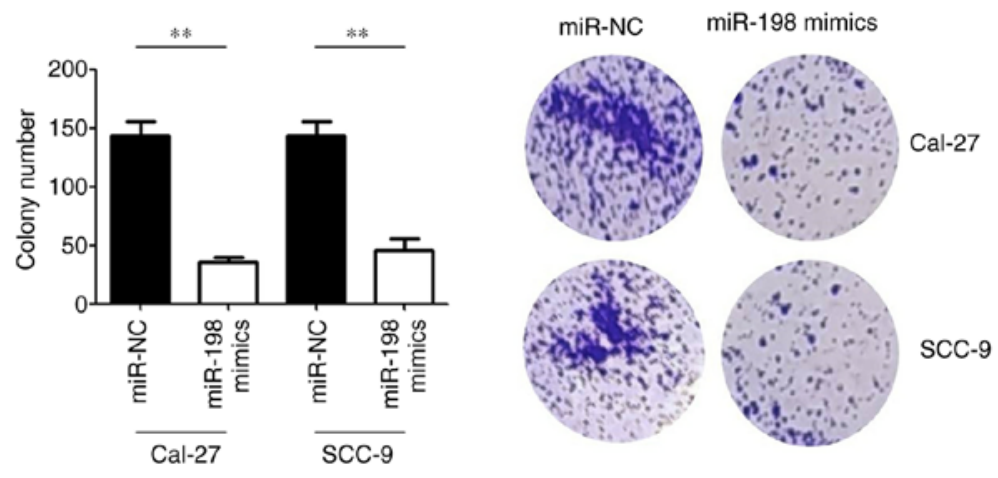

D
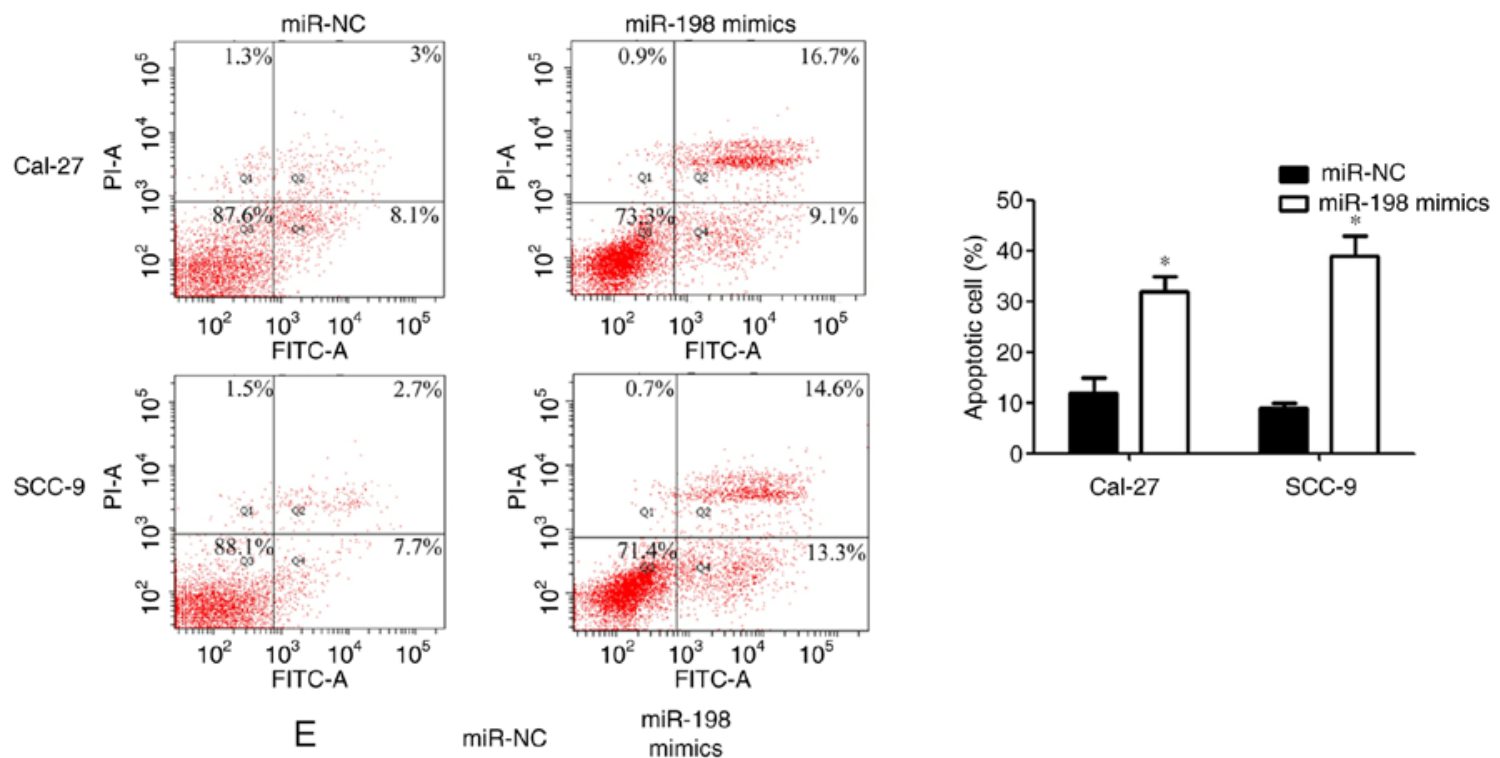

E
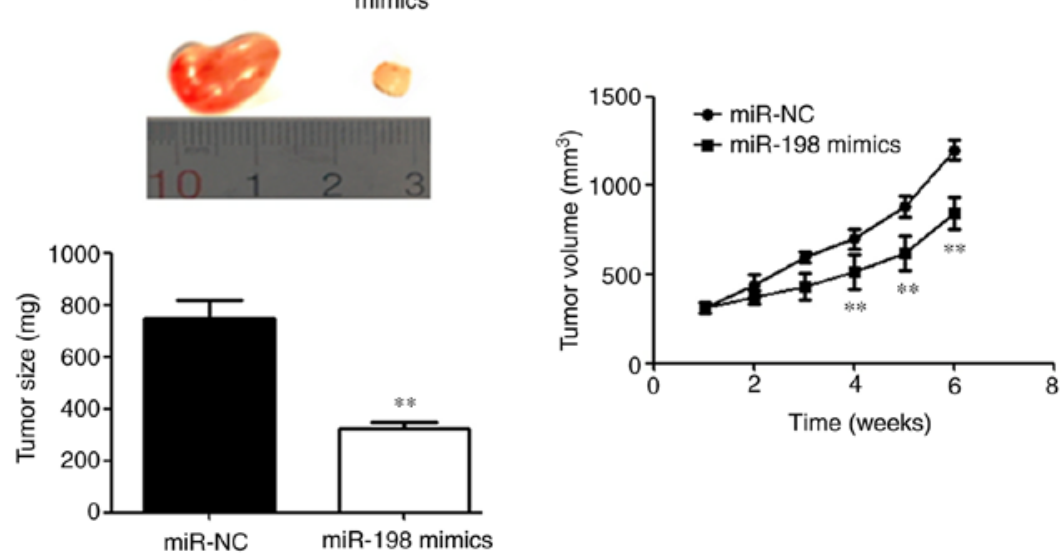

Figure 2. miR-198 upregulation inhibits OSCC cell proliferation and induces cell apoptosis in vitro and in vivo. OSCC cells were transfected with miR-198 mimics or NC. (A) Reverse transcription-quantitative PCR analysis of the transfection efficiency. Cell proliferation was determined using (B) MTS and (C) colony formation assays. (D) Apoptosis was examined through Annexin V/PI staining. (E) Tumour sizes were analysed at the endpoint of the xenograft experiment and tumour volumes were determined at the indicated time points. Scale bar, $1 \mathrm{~cm} .{ }^{*} \mathrm{P}<0.05,{ }^{* * *} \mathrm{P}<0.01 \mathrm{vs}$. miR-NC group. miR, microRNA; OSCC, oral squamous cell carcinoma; NC, negative control. 
A

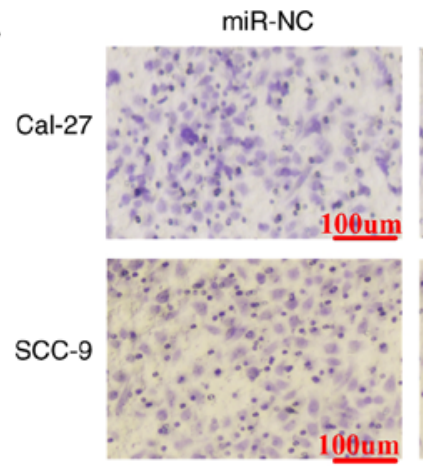

miR-198 mimics

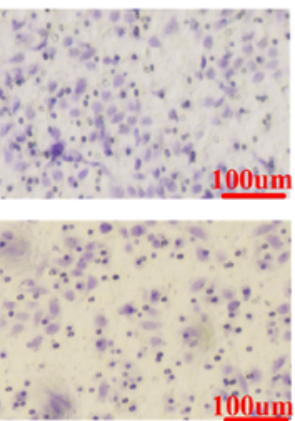

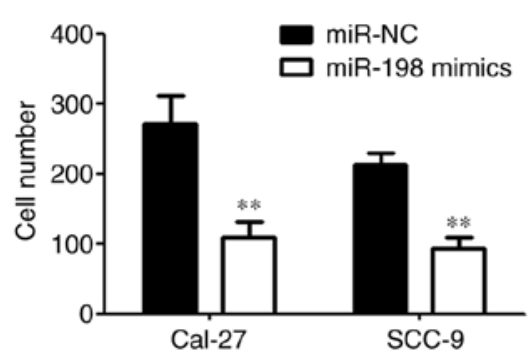

B

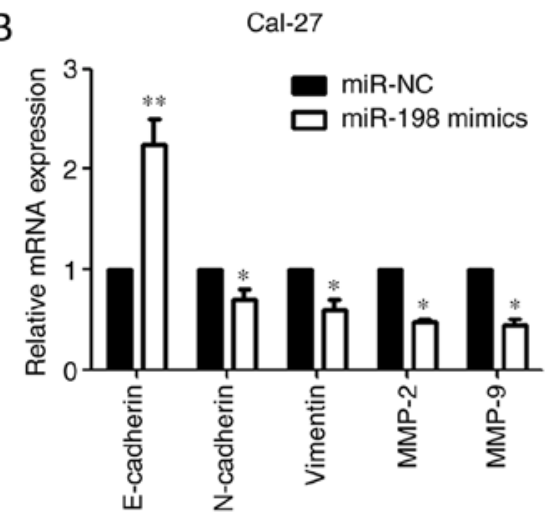

C

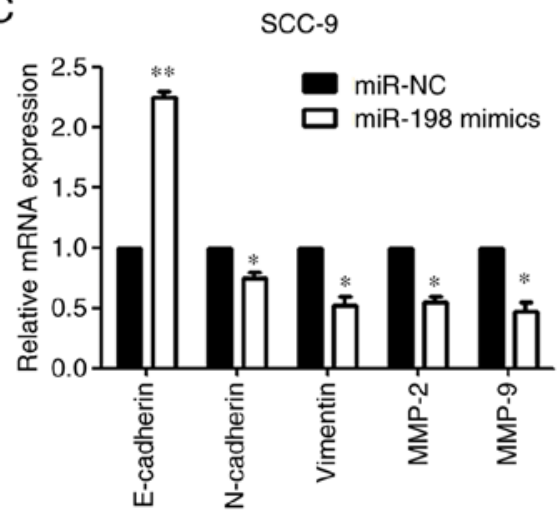

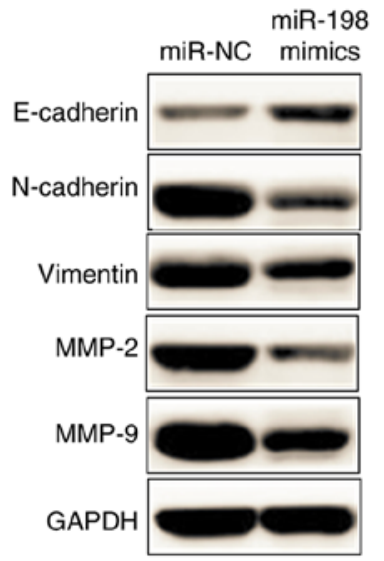

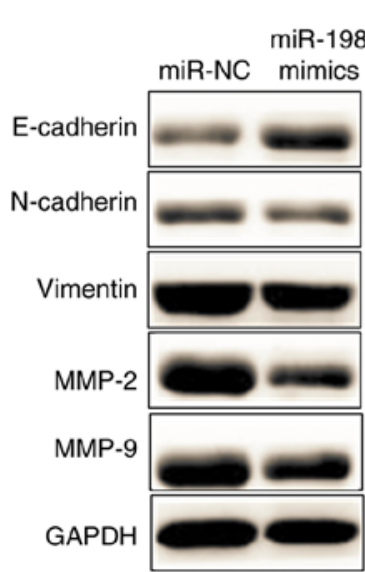

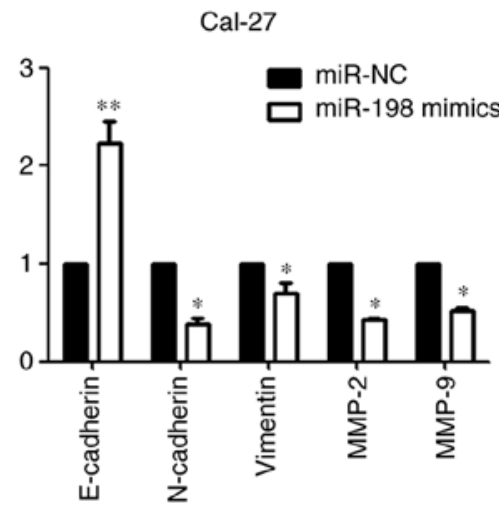

SCC-9

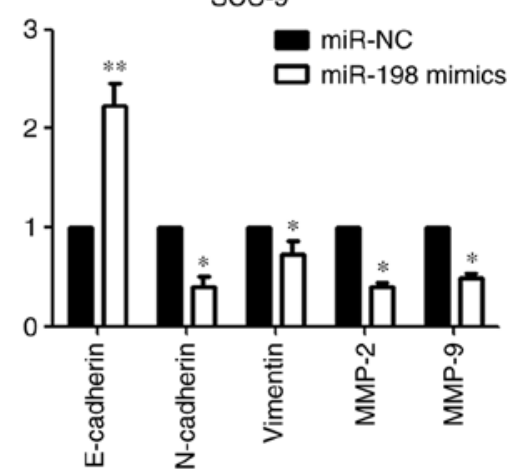

D

Cal-27

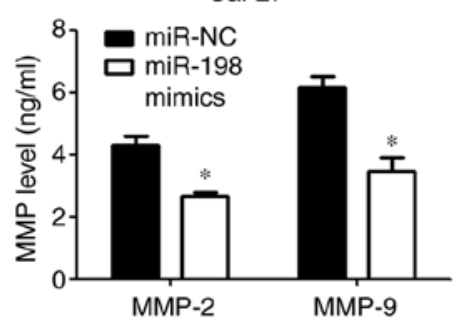

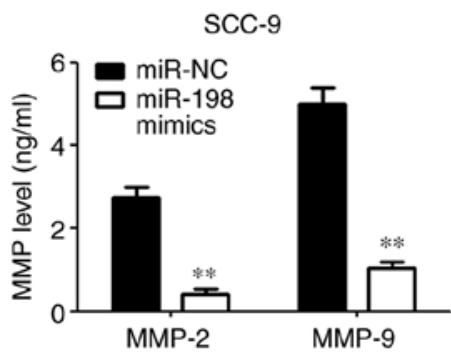

Figure 3. miR-198 upregulation inhibits OSCC cell invasion and epithelial-mesenchymal transition. OSCC cells were transfected with miR-198 mimics or NC. (A) Cell invasion was determined using a Transwell assay. Scale bar, $100 \mu \mathrm{m}$. The overexpression of miR-198 significantly increased the expression of E-cadherin, while decreasing the expression of N-cadherin, vimentin, MMP-2 and MMP-9 in (B) Cal-27 and (C) SCC-9 cells. (D) Levels of MMP-2 and MMP-9 in the culture supernatants were detected using ELISA. "P $<0.05,{ }^{* *} \mathrm{P}<0.01$ vs. miR-NC group. miR, microRNA; OSCC, oral squamous cell carcinoma; NC, negative control.

survival (OS) and disease-free survival (DFS) outcomes were analysed. Pearson's correlation analysis was used to detect the correlation between miR-198 and CDK4 expression in OSCC tissues. Univariate and multivariate analyses were conducted according to the Cox regression model. $\mathrm{P}<0.05$ was considered to indicate a statistically significant difference. 
A

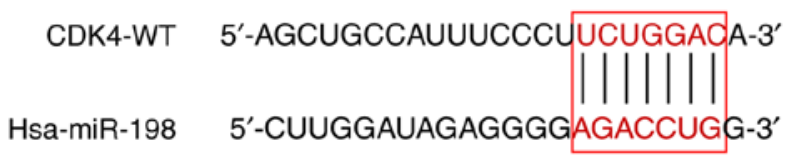

CDK4-MUT 5'-AGCUGCCAUUUCCCUAGACCUGA-3'

B

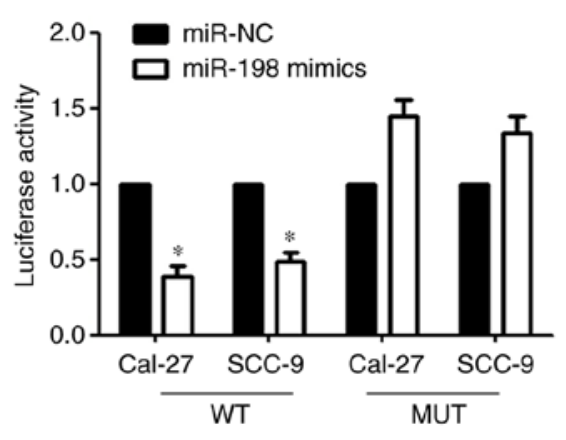

D

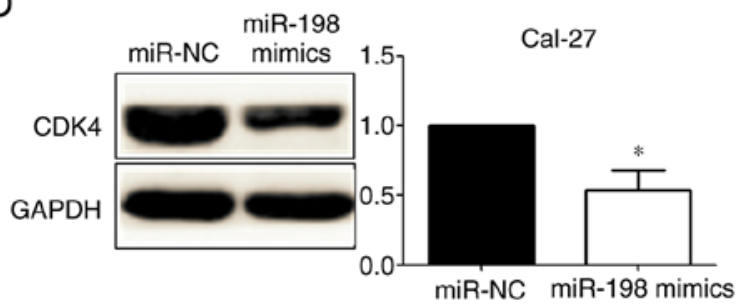

C
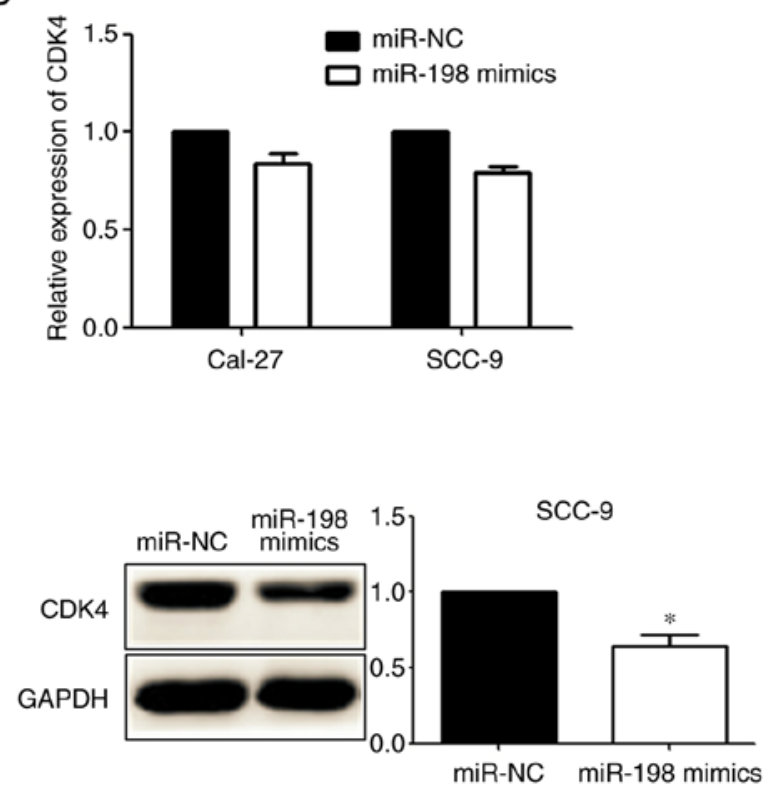

Figure 4. miR-198 inhibits CDK4 expression by targeting the 3'UTR of CDK4 in OSCC cells. (A) Diagram of the miR-198 binding site in the 3'UTR of CDK4. (B) The overexpression of miR-198 inhibited the luciferase activity in OSCC cells. (C) The overexpression of miR-198 could not inhibit the mRNA expression of CDK4 in OSCC cells, as determined via reverse transcription-quantitative PCR. (D) The overexpression of miR-198 inhibited the protein expression of CDK4 in OSCC cells, as determined via western blotting. " $\mathrm{P}<0.05$ vs. miR-NC group. miR, microRNA; OSCC, oral squamous cell carcinoma; NC, negative control; CDK4, cyclin-dependent kinase 4; WT, wild-type; MUT, mutant; UTR, untranslated region.

A

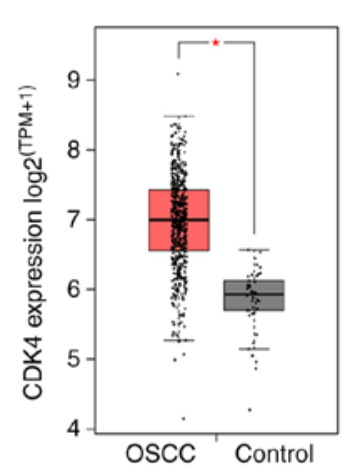

D

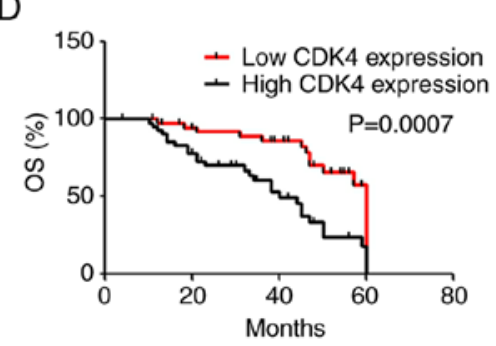

B

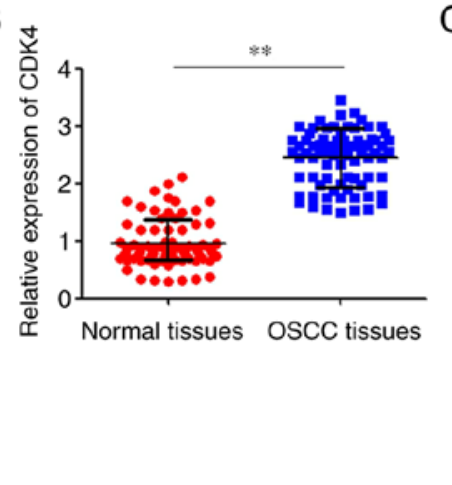

E

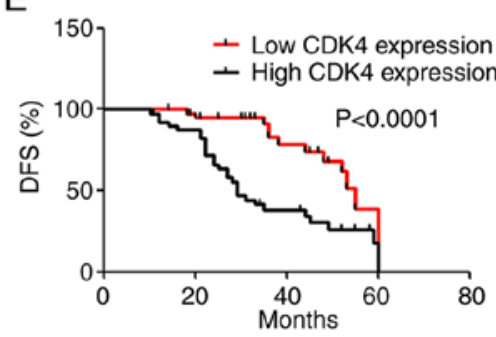

C

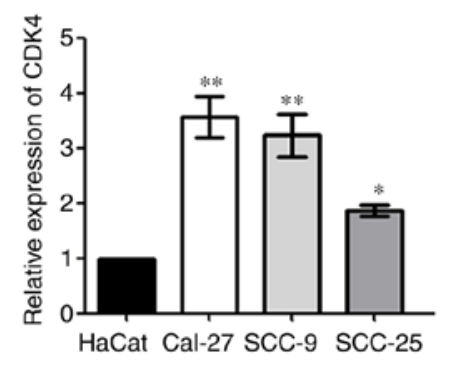

$\mathrm{F}$

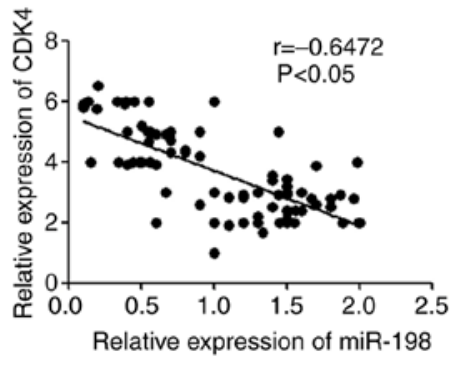

Figure 5. Expression of CDK4 in OSCC tissues and cells. (A) The expression of CDK4 in OSCC and control (GEPIA2, box plot, TPM). "P<0.05. (B) CDK4 expression in OSCC and normal tissues, as determined via RT-qPCR. ${ }^{* *} \mathrm{P}<0.01$. (C) CDK4 expression OSCC cell lines and the HaCat cells were examined via RT-qPCR. "P $<0.05,{ }^{* *} \mathrm{P}<0.01$ vs. HaCat cells. The Kaplan-Meier method was used to compare the (D) OS and (E) DSF rates based on CDK4 expression. (F) A negative correlation was observed between the expression levels of CDK4 and miR-198 in OSCC tissues. miR, microRNA; OSCC, oral squamous cell carcinoma; CDK4, cyclin-dependent kinase 4; RT-qPCR, reverse transcription-quantitative PCR; OS, overall survival; DFS, disease-free survival; TPM, transcripts per million. 
A

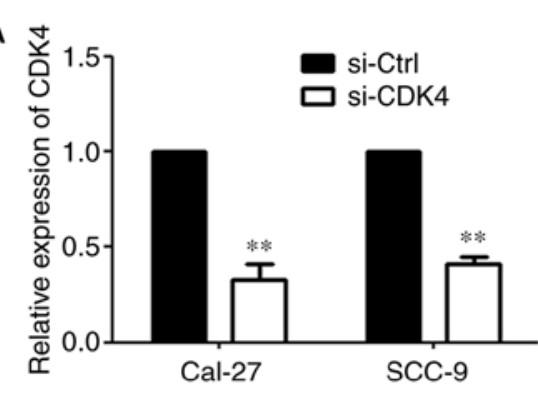

C
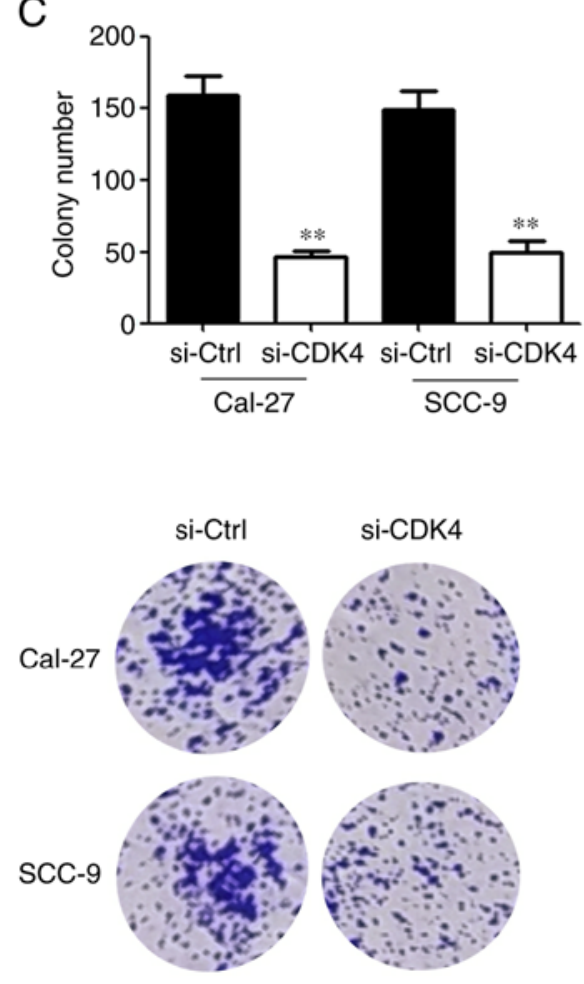

B

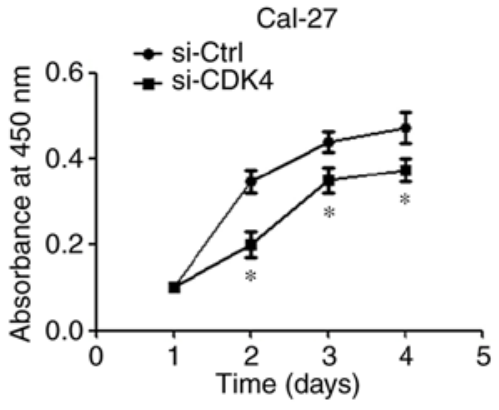

D
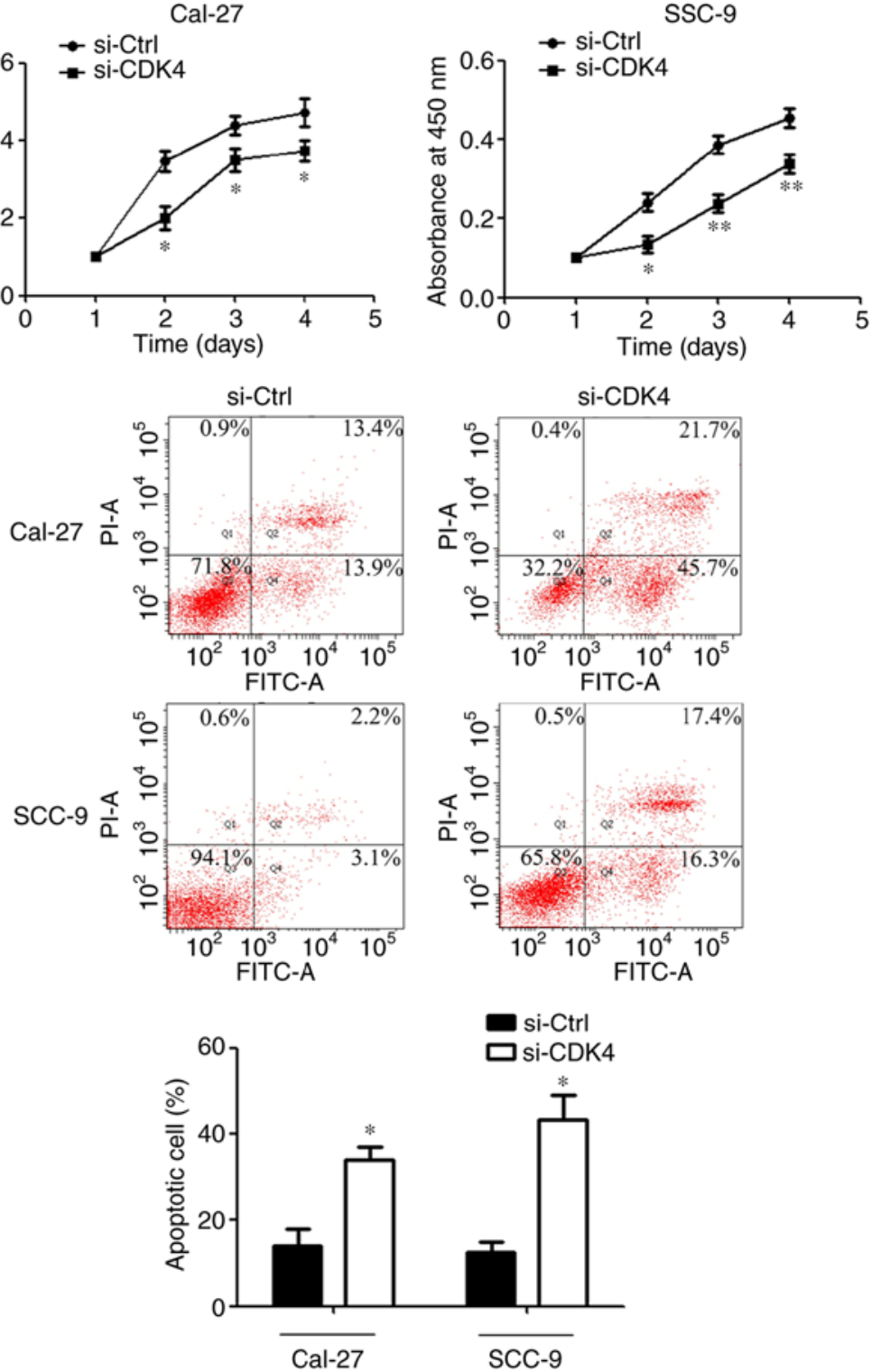

Figure 6. Effects of CDK4 silencing on cell proliferation and apoptosis. Oral squamous cell carcinoma cells were transfected with si-CDK4 or si-Ctrl. (A) mRNA expression of CDK4 was examined via reverse transcription-quantitative PCR. Cell proliferation was determined using (B) MTS and (C) colony formation assays. (D) Apoptosis was examined using Annexin V/PI staining. ${ }^{*} \mathrm{P}<0.05,{ }^{* *} \mathrm{P}<0.01$ vs. si-Ctrl group. CDK4, cyclin-dependent kinase 4 ; si-, small interfering RNA.

\section{Results}

miR-198 is downregulated in OSCC. To investigate miR-198 expression in OSCC, miR-198 expression in OSCC tissues and the corresponding adjacent tissues was primarily analysed using RT-qPCR. It was found that miR-198 was downregulated in OSCC tissues compared with the normal tissues (Fig. 1A). The level of miR-198 expression in patients with metastasis was significantly decreased compared with patients with OSCC without metastasis (Fig. 1B). Moreover, RT-qPCR assays showed that miR-198 expression was reduced in all OSCC cell lines compared with HaCat cells (Fig. 1C). Expression was the most significantly reduced in the Cal-27 and SCC-9 cell lines, thus these cells were then chosen for further assays. Patients with OSCC with low miR-198 expression had poorer OS and DFS compared with patients with a high expression (Fig. 1D and E).
The cox proportional hazard model was used to determine the impact of miR-198 expression and the clinicopathological factors on the prognosis of patients with OSCC. Univariate Cox regression analysis showed that the differentiation $(\mathrm{P}=0.030$ for OS; $\mathrm{P}=0.034$ for $\mathrm{DFS})$, TNM stage $(\mathrm{P}=0.039$ for $\mathrm{OS}$; $\mathrm{P}=0.031$ for DFS) and miR-198 expression $(\mathrm{P}=0.025$ for $\mathrm{OS}$; $\mathrm{P}=0.022$ for $\mathrm{DFS}$ ) were significantly associated with poor OS and DFS. Multivariate analyses showed that the TNM stage $(\mathrm{P}=0.043$ for OS; $\mathrm{P}=0.033$ for $\mathrm{DFS}$ ) and miR-198 expression $(\mathrm{P}=0.033$ for $\mathrm{OS} ; \mathrm{P}=0.027$ for $\mathrm{DFS}$ ) were associated with poor OS and DFS (Table I).

Upregulation of miR-198 suppresses the proliferation and promotes the apoptosis of OSCC cells. RT-qPCR was used to detect transfection efficiency after cells were transfected with miR-198 mimics (Fig. 2A). MTS assays showed that compared 
A

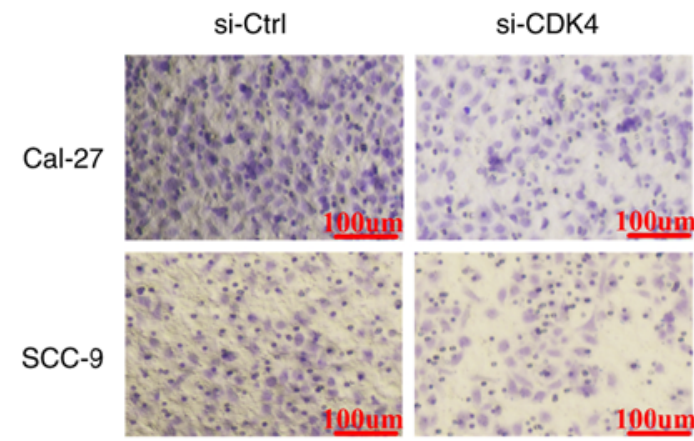

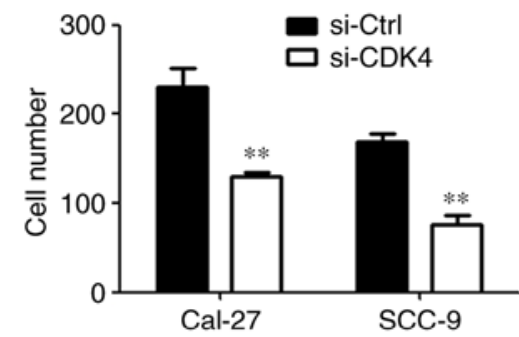

Cal-27
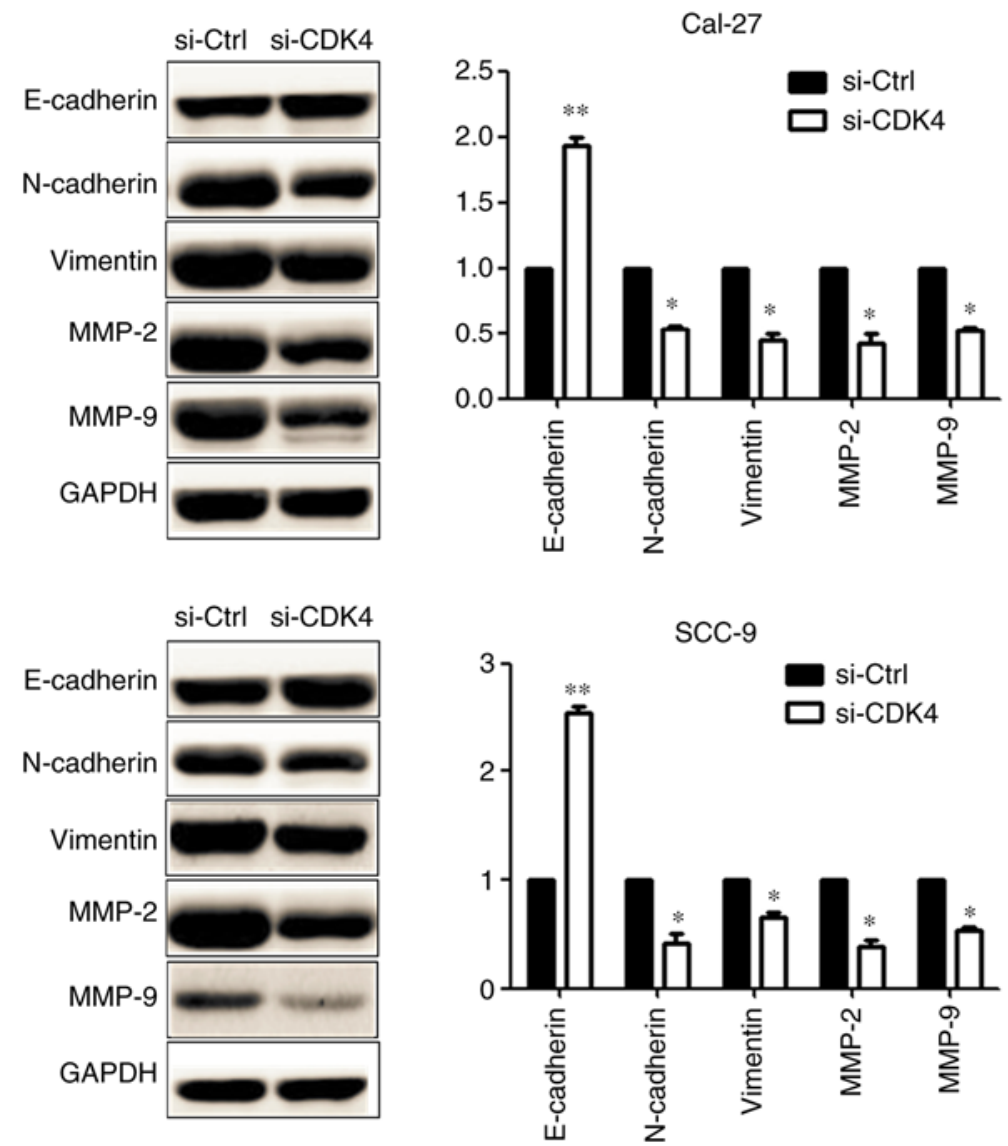

Figure 7. Effects of CDK4 knockdown on cell invasion and epithelial-mesenchymal transition. Oral squamous cell carcinoma cells were transfected with si-CDK4 or si-Ctrl. (A) Cell invasion was determined using a Transwell assay. Scale bar, $100 \mu \mathrm{m}$. CDK4 knockdown significantly increased the expression of E-cadherin, while decreasing the expression of N-cadherin, vimentin, MMP-2 and MMP-9, in (B) Cal-27 cells and (C) SCC-9 cells. ${ }^{*} \mathrm{P}<0.05,{ }^{* *} \mathrm{P}<0.01$ vs. si-Ctrl group. CDK4, cyclin-dependent kinase 4; si-, small interfering RNA.

with the miR-NC group, the proliferative activity of OSCC cells was decreased after transfection with miR-198 mimics at different observation time points (Fig. 2B). Consistent with this finding, the colony formation ability of OSCC cells was significantly reduced after miR-198 mimic transfection (Fig. 2C). Subsequently, the flow cytometry results showed that the percentage of apoptotic cells significantly increased after miR-198 mimics transfection (Fig. 2D). Xenograft experiments also showed a significant reduction in tumour size and volume when miR-198 was overexpressed (Fig. 2E). Taken together, these data indicated that miR-198 may function as a tumour suppressor in OSCC.

Upregulation of miR-198 suppresses invasion and EMT in OSCC cells. Transwell assays showed that compared with the miR-NC group, the number of invading OSCC cells was decreased significantly after transfection with miR-198 mimics (Fig. 3A). RT-qPCR and western blotting results showed that the overexpression of miR-198 significantly increased the level of E-cadherin, and decreased the levels of N-cadherin, vimentin, MMP-2 and MMP-9, in OSCC cells (Fig. 3B and C). ELISA showed that the concentration of MMP-2 and MMP-9 was decreased significantly after transfection with miR-198 mimics (Fig. 3D). Taken together, these data indicated that miR-198 may function as a tumour suppressor in OSCC.

CDK4 is a direct target of $m i R-198$ in OSCC. TargetScan showed that there was a miR-198 binding sequence in the 3'UTR of CDK4 (Fig. 4A). Dual-luciferase reporter assays 
A

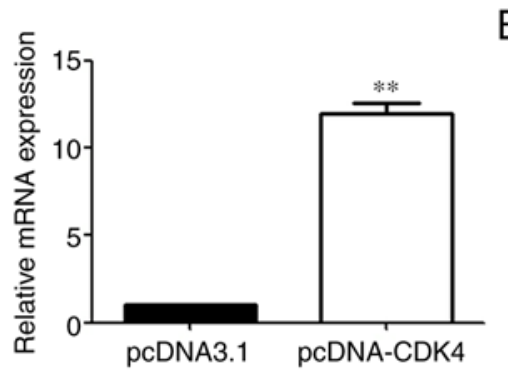

B

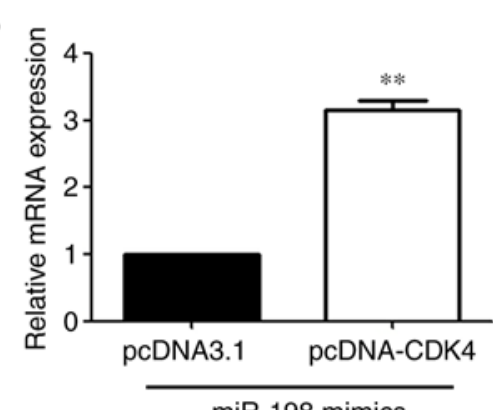

C

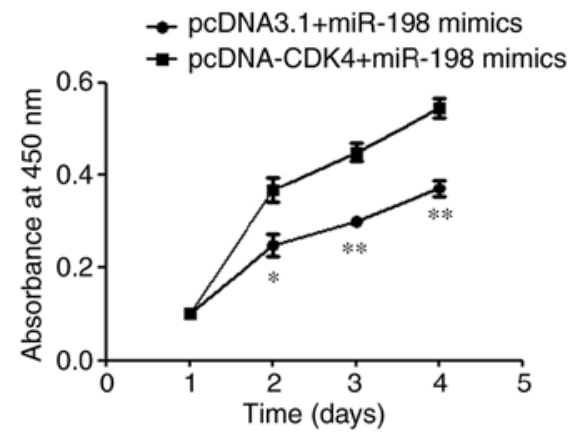

D
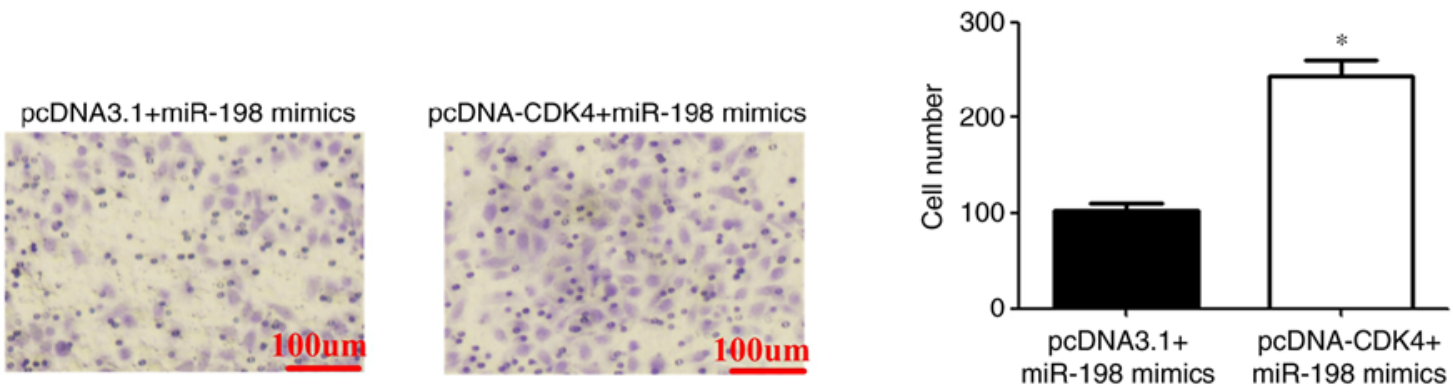

E
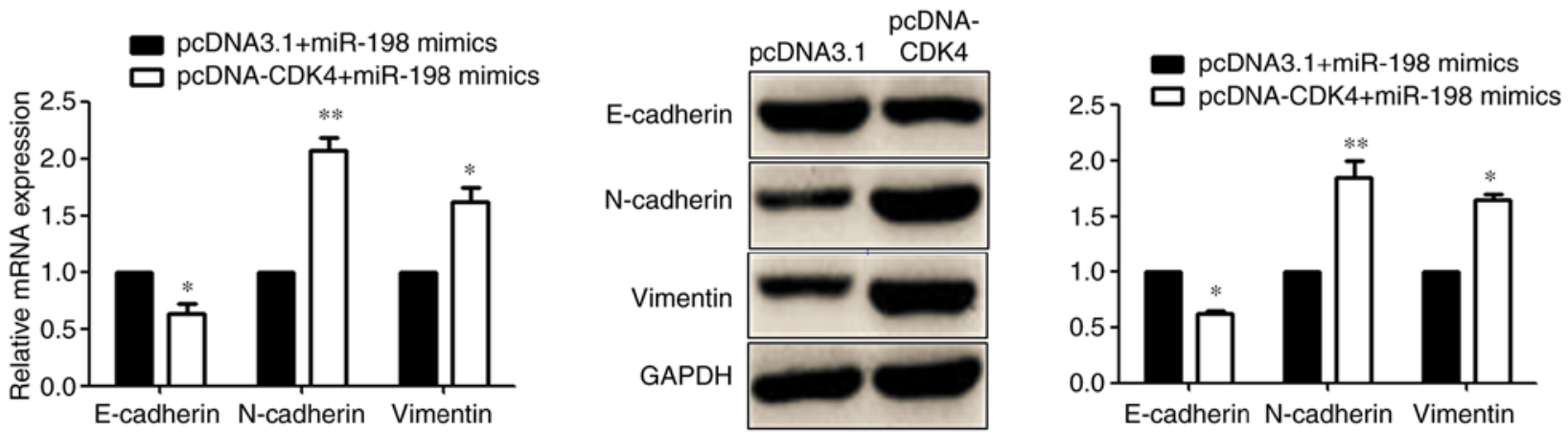

Figure 8. Overexpression of CDK4 partially promotes cell proliferation, invasion and epithelial-mesenchymal transition in oral squamous cell carcinoma cells. (A) mRNA expression of CDK4 was examined via RT-qPCR after transfection with pcDNA-CDK4 or pcDNA3.1. ${ }^{* *} \mathrm{P}<0.01$ vs. pcDNA3.1 group. Then, Cal-27 cells were co-transfected with pcDNA3.1 + miR-198 mimics or pcDNA-CDK4 + miR-198 mimics. (B) mRNA expression of CDK4 was determined via RT-qPCR. (C) Cell proliferation was assessed using an MTS assay. (D) Cell invasion was determined using a Transwell assay. Scale bar, $100 \mu \mathrm{m}$. (E) The overexpression of CDK4 significantly decreased the level of E-cadherin, and increased $\mathrm{N}$-cadherin and vimentin, in $\mathrm{Cal}-27$ cells. ${ }^{*} \mathrm{P}<0.05,{ }^{* *} \mathrm{P}<0.01$ vs pcDNA3.1 + miR-198 mimics group. CDK4, cyclin-dependent kinase 4; RT-qPCR, reverse transcription-quantitative PCR; miR, microRNA.

showed that the overexpression of miR-198 could inhibit CDK4-WT reporter activity, but not the activity of the CDK4-MUT construct in OSCC cells, demonstrating that miR-198 could specifically target the CDK4-3'UTR by binding to the seed sequence (Fig. 4B). RT-qPCR showed that there were no obvious changes in CDK4 mRNA expression after transfection with miR-198 mimics (Fig. 4C). Western blotting showed that transfection with miR-198 mimics significantly decreased the expression of CDK4 protein (Fig. 4D). Taken together, these data indicated that miR-198 targets CDK4 directly in OSCC cells.

CDK4 is upregulated in OSCC. From the GEPIA2 database, it was found that CDK4 expression was higher in OSCC tissues than that in controls (Fig. 5A). RT-qPCR showed that CDK4 mRNA expression was upregulated in OSCC tissues compared with the normal tissues (Fig. 5B). Moreover, RT-qPCR showed that there were higher expression levels of CDK4 in OSCC cell lines compared with HaCat cells (Fig. 5C). Patients with
OSCC with high CDK4 expression had poorer OS and DFS than patients with a low expression (Fig. 5D and E). RT-qPCR analysis also showed that miR-198 was moderately negatively correlated with CDK4 expression in patients with OSCC (Fig. 5F). Taken together, these data indicated that CDK4 expression may be involved in OSCC progression.

Downregulation of CDK4 suppresses the proliferation and promotes the apoptosis of OSCC cells. RT-qPCR was performed to detect the transfection efficiency after si-CDK4 was transfected (Fig. 6A). MTS assays showed that compared with the si-Ctrl group, the proliferative activity of OSCC cells was decreased after transfection of si-CDK4 at different observation time points (Fig. 6B). Consistent with this finding, the colony formation ability of OSCC cells was significantly reduced after transfection with si-CDK4 (Fig. 6C). Subsequently, the results of flow cytometry showed that the percentage of apoptotic cells was significantly increased after transfection with si-CDK4 (Fig. 6D). Taken together, these 
data indicated that $\mathrm{CDK} 4$ may function as a tumour promoter in OSCC.

Downregulation of CDK4 suppresses invasion and EMT in OSCC cells. Transwell assays showed that compared with the si-Ctrl group, the number of invading OSCC cells was significantly decreased after transfection with si-CDK4 (Fig. 7A). RT-qPCR and western blotting results showed that knockdown of CDK4 expression significantly increased the level of E-cadherin, and decreased the levels of N-cadherin, vimentin, MMP-2 and MMP-9, in OSCC cells (Fig. 7B and C). Collectively, these data indicated that $\mathrm{CDK} 4$ may function as a tumour promoter in OSCC.

Addition of CDK4 reverses the miR-198-mediated inhibitory effect on proliferation, invasion and EMT in OSCC cells. A representation vector that encoded the entire CDK4 coding sequence and lacked the 3'UTR was constructed. RT-qPCR was used to detect the transfection efficiency after pcDNA-CDK4 was transfected (Fig. 8A). Then, pcDNA-CDK4 or its NC was co-transfected with the miR-198 mimic into Cal-27 cells. RT-qPCR showed that CDK4 expression was significantly increased after co-transfection of pcDNA-CDK4 + miR-198 mimics compared with the pcDNA3.1 + miR-198 mimic group (Fig. 8B). MTS assays showed that the concomitant overexpression of miR-198 and CDK4 abrogated the inhibitory effects of transfection with pcDNA3.1 + miR-198 mimic (Fig. 8C). Transwell assays also showed that CDK4 overexpression reversed the inhibitory effects of transfection with pcDNA3.1 + miR-198 mimic on the invasion of Cal-27 cells (Fig. 8D). Moreover, RT-qPCR and western blotting showed that the overexpression of CDK4 decreased the level of E-cadherin, and increased N-cadherin and vimentin, in Cal-27 cells compared with the pcDNA3.1 + miR-198 mimic group (Fig. 8E). Taken together, these findings revealed that CDK4 reversed the miR-198-mediated inhibitory effect in OSCC cells.

\section{Discussion}

Increasing evidence has demonstrated that abnormal miRNA expression is detected in OSCC, and some of these miRNAs are involved in modulating OSCC cell proliferation and metastasis $(21,22)$. Liang et al (23) found that miR-1297 expression is significantly decreased in OSCC tumours compared with that in adjacent non-tumour tissues, and the overexpression of miR-1297 could suppress the cell proliferation of SSC-4 cells in vitro (23). In addition, Nagai et al (24) demonstrated that miR-205-5p could suppress the invasiveness of OSCC by inhibiting metalloproteinase inhibitor 2 expression. The present study confirmed a low expression of miR-198 in clinical tumour tissues, which was consistent with the results of other studies on several different types of tumours (12-14). Furthermore, the expression of miR-198 in patients with metastasis was significantly lower than that in patients without metastasis. OSCC metastasis can be classified as lymphatic metastasis or vascular invasion, which significantly impacts patient prognosis (25). Previous studies have reported that miR-198 is a key molecule that is responsible for vascular invasion (26-28). To investigate the effects of miR-198 on OSCC prognosis, its prognostic ability in patients with OSCC was examined. It was found that a low miR-198 expression was significantly related to a poor OS and DFS in patients with OSCC.

The previously identified targets of miR-198 vary widely in structure and function depending on the cancer type investigated. Yang et al (13) confirmed that miR-198 can inhibit the proliferation of lung cancer cells and induce apoptosis by targeting the fibroblast growth factor receptor in lung cancer. Wang et al (20) demonstrated that miR-198 targets fucosyltransferase 8 and can inhibit tumour growth and metastasis in colorectal cancer. Moreover, Ye et al (29) found that miR-198 could inhibit livin expression, indicating that miR-198 was associated with cell apoptosis by targeting livin in prostate cancer cells. Through the investigation of non-cancer cells, it has also been found that miR-198 overexpression can inhibit cell proliferation in keratinocyte cell lines, and significantly arrest cells at the G1 phase, as detected by cell cycle analysis, by targeting cyclinD2 (30). In prostate cancer cell lines, by targeting E3 ubiquitin-protein ligase MIB1, overexpression of miR-198 has also been found to increase G0/G1 cell cycle arrest and inhibit proliferation (31). In the present study, using a dual-luciferase reporter assay, it was confirmed that miR-198 suppressed CDK4 levels by binding to the 3'UTR of the oncogene. To the best of the authors' knowledge, this study is the first to present the effects of miR-198 in OSCC cell proliferation, apoptosis and invasion.

CDK genes belong to the serine/threonine kinase family and are involved in the cell cycle pathway. CDK genes form a complex with G1/S-specific cyclin-D1 and phosphorylates retinoblastoma-associated protein gene (32). As a member of the CDK family, CDK4 is an essential signalling transduction molecule, which participates in cell cycle and apoptosis by binding to cyclin proteins (33). Its concentration and activation are closely related to the transformation rate of the G1/S phase of the cell cycle (34). The deregulation of CDK4 expression is associated with several aspects of tumorigenesis, including cell proliferation, cycle arrest and abnormal apoptosis (35). There is growing evidence that more cells undergo apoptosis when CDK4 is knocked down in non-small cell lung, oesophageal and breast cancer (36-38). In the present study, it was found that CDK4 was highly expressed in most OSCC tissues and that the proliferative ability of OSCC cells was inhibited after the knockdown of CDK4, Moreover, metastasis and EMT were reduced. Furthermore, the overexpression of CDK4 counteracted the miR-198-mediated effects on cell behaviours, which also indicated that the presence of CDK4 worsened the outcome in OSCC cells.

In conclusion, the results of the present study showed that the overexpression of miR-198 could suppress tumour growth and metastasis in OSCC cells by targeting CDK4. Therefore, the miR-198/CDK4 axis may be considered as a novel prognostic marker and therapeutic target in OSCC.

\section{Acknowledgements}

Not applicable.

\section{Funding}

The present study was supported by the Natural Science Foundation of China (grant no. 82002886). 


\section{Availability of data and materials}

The datasets used and/or analysed during the present study are available from the corresponding author on reasonable request.

\section{Authors' contributions}

YK designed the experiments. YZ and YS analysed the data. YK and YS performed the experiments. YK wrote the paper. YK and YZ confirm the authenticity of all the raw data. All authors read and approved the final manuscript.

\section{Ethics approval and consent to participate}

All research protocols were approved by the ethics committee of the School and Hospital of Stomatology, China Medical University (Shenyang, China) and written informed consent was obtained from the donors.

\section{Patient consent for publication}

Not applicable.

\section{Competing interests}

The authors declare that they have no competing interests.

\section{References}

1. Zhang S, Wang X, Gupta A, Fang X, Wang L and Zhang C: Expression of IL-17 with tumor budding as a prognostic marker in oral squamous cell carcinoma. Am J Transl Res 11: 1876-1883, 2019.

2. Wu K, Jiang Y, Zhou W, Zhang B, Li Y, Xie F, Zhang J, Wang X Yan M, Xu Q, et al: Long noncoding RNA RC3H2 facilitates cell proliferation and invasion by targeting MicroRNA-101-3p/EZH2 Axis in OSCC. Mol Ther Nucleic Acids 20: 97-110, 2020.

3. Chen L, Zhang S, Wu J, Cui J, Zhong L, Zeng L and Ge S: circRNA_100290 plays a role in oral cancer by functioning as a sponge of the miR-29 family. Oncogene 36: 4551-4561, 2017.

4. Zhao Z, Gao D, Ma T and Zhang L: MicroRNA-141 suppresses growth and metastatic potential of head and neck squamous cell carcinoma. Aging (Albany NY) 11: 921-932, 2019.

5. Wang Y, Guo W, Li Z, Wu Y, Jing C, Ren Y, Zhao M, Kong L, Zhang C, Dong J, et al: Role of the EZH2/miR-200 axis in STAT3-mediated OSCC invasion. Int J Oncol 52: 1149-1164, 2018.

6. Bartel DP: MicroRNAs: Target recognition and regulatory functions. Cell 136: 215-233, 2009.

7. Flynt AS and Lai EC: Biological principles of microRNA-mediated regulation: Shared themes amid diversity. Nat Rev Genet 9: 831-842, 2008

8. Zhang B, Li Y, Hou D, Shi Q, Yang S and Li Q: MicroRNA-375 inhibits growth and enhances radiosensitivity in oral squamous cell carcinoma by targeting insulin like growth factor 1 receptor. Cell Physiol Biochem 42: 2105-2117, 2017.

9. Wang K, Jin J, Ma T and Zhai H: MiR-139-5p inhibits the tumorigenesis and progression of oral squamous carcinoma cells by targeting HOXA9. J Cell Mol Med 21: 3730-3740, 2017.

10. Fu S, Chen HH, Cheng P, Zhang CB and Wu Y: MiR-155 regulates oral squamous cell carcinoma Tca8113 cell proliferation, cycle and apoptosis via regulating p27Kip1. Eur Rev Med Pharmacol Sci 21: 937-944, 2017

11. $\mathrm{Yu} \mathrm{EH}, \mathrm{Tu} \mathrm{HF}$, Wu $\mathrm{CH}$, Yang $\mathrm{CC}$ and Chang $\mathrm{KW}$ : MicroRNA-21 promotes perineural invasion and impacts survival in patients with oral carcinoma. J Chin Med Assoc 80: 383-388, 2017.

12. Hu Y, Tang Z, Jiang B, Chen J and Fu Z: MiR-198 functions as a tumor suppressor in breast cancer by targeting CUB domain-containing protein 1. Oncol Lett 13: 1753-1760, 2017.
13. Yang J, Zhao H, Xin Y and Fan L: MicroRNA-198 inhibits proliferation and induces apoptosis of lung cancer cells via targeting FGFR1. J Cell Biochem 115: 987-995, 2014.

14. Tan S, Li R, Ding K, Lobie PE and Zhu T: MiR-198 inhibits migration and invasion of hepatocellular carcinoma cells by targeting the HGF/c-MET pathway. FEBS Lett 585: 2229-2234, 2011.

15. Cui Z, Zheng X and Kong D: Decreased miR-198 expression and its prognostic significance in human gastric cancer. World J Surg Oncol 14: 33, 2016.

16. Yamamoto K, Kawaguchi M, Shimomura T, Izumi A, Konari K, Honda A, Lin CY, Johnson MD, Yamashita Y, Fukushima T and Kataoka $\mathrm{H}$ : Hepatocyte growth factor activator inhibitor type-2 (HAI-2)/SPINT2 contributes to invasive growth of oral squamous cell carcinoma cells. Oncotarget 9: 11691-11706, 2018.

17. Hu Q, Wu T, Chen X, Li H, Du Z, Hao Y, Peng J, Tai S, Song M and Cheng B: The poor outcome of second primary oral squamous cell carcinoma is attributed to Bmil upregulation. Cancer Med 7: 1056-1069, 2018.

18. Livak KJ and Schmittgen TD: Analysis of relative gene expression data using real-time quantitative PCR and the 2(-Delta Delta C(T)) method. Methods 25: 402-408, 2001.

19. Zhong F, Chen H, Han L, Jin Y and Wang W: Curcumin attenuates lipopolysaccharide-induced renal inflammation. Biol Pharm Bull 34: 226-232, 2011.

20. Wang M, Wang J, Kong X, Chen H, Wang Y, Qin M, Lin Y, Chen $\mathrm{H}, \mathrm{Xu} \mathrm{J}$, Hong J, et al: MiR-198 represses tumor growth and metastasis in colorectal cancer by targeting fucosyl transferase 8 . Sci Rep 4: 6145, 2014.

21. Cheng CM, Shiah SG, Huang CC, Hsiao JR and Chang JY: Up-regulation of miR-455-5p by the TGF- $\beta$-SMAD signalling axis promotes the proliferation of oral squamous cancer cells by targeting UBE2B. J Pathol 240: 38-49, 2016.

22. Chang KW, Kao SY, Wu YH, Tsai MM, Tu HF, Liu CJ, Lui MT and Lin SC: Passenger strand miRNA miR-31* regulates the phenotypes of oral cancer cells by targeting RhoA. Oral Oncol 49: 27-33, 2013.

23. Liang L, Feng L and Wei B: MicroRNA-1297 involves in the progression of oral squamous cell carcinoma through PTEN. Saudi J Biol Sci 25: 923-927, 2018.

24. Nagai H, Hasegawa S, Uchida F, Terabe T, Ishibashi Kanno N, Kato K, Yamagata K, Sakai S, Kawashiri S, Sato H, et al: MicroRNA-205-5p suppresses the invasiveness of oral squamous cell carcinoma by inhibiting TIMP-2 expression. Int J Oncol 52: 841-850, 2018.

25. Adel M, Kao HK, Hsu CL, Huang JJ, Lee LY, Huang Y, Browne T, Tsang NM, Chang YL and Chang KP: Evaluation of lymphatic and vascular invasion in relation to clinicopathological factors and treatment outcome in oral cavity squamous cell carcinoma. Medicine (Baltimore) 94: e1510, 2015.

26. Mattiotti A, Prakash S, Barnett P and van den Hoff MJB: Follistatin-like 1 in development and human diseases. Cell Mol Life Sci 75: 2339-2354, 2018.

27. Liao C, Huang X, Gong Y and Lin Q: Discovery of core genes in colorectal cancer by weighted gene co-expression network analysis. Oncol Lett 18: 3137-3149, 2019.

28. Shi Y, Fang N, Li Y, Guo Z, Jiang W, He Y, Ma Z and Chen Y: Circular RNA LPAR3 sponges microRNA-198 to facilitate esophageal cancer migration, invasion, and metastasis. Cancer Sci 111: 2824-2836, 2020.

29. Ye L, Li S, Ye D, Yang D, Yue F, Guo Y, Chen X, Chen F, Zhang $\mathrm{J}$ and Song $\mathrm{X}$ : Livin expression may be regulated by miR-198 in human prostate cancer cell lines. Eur J Cancer 49: 734-740, 2013.

30. Wang J, Dan G, Shangguan T, Hao H, Tang R, Peng K, Zhao J, Sun H and Zou Z: MiR-198 represses the proliferation of HaCaT cells by targeting cyclin D2. Int J Mol Sci 16: 17018-17028, 2015.

31. Ray J, Hoey C, Huang X, Jeon J, Taeb S, Downes MR, Boutros PC and Liu SK: MicroRNA-198 suppresses prostate tumorigenesis by targeting MIB1. Oncol Rep 42: 1047-1056, 2019.

32. Wood DJ and Endicott JA: Structural insights into the functional diversity of the CDK-cyclin family. Open Biol 8: 180112, 2018.

33. Hamilton E and Infante JR: Targeting CDK4/6 in patients with cancer. Cancer Treat Rev 45: 129-138, 2016.

34. Gao X, Leone GW and Wang H: Cyclin D-CDK4/6 functions in cancer. Adv Cancer Res 148: 147-169, 2020.

35. Sheppard KE and AbuHammad S: CDK4/6 inhibition in cancer: The cell cycle splicing connection. Mol Cell Oncol 6: e1673643, 2019. 
36. Feng H, Ge F, Du L, Zhang Z and Liu D: MiR-34b-3p represses cell proliferation, cell cycle progression and cell apoptosis in non-small-cell lung cancer (NSCLC) by targeting CDK4. J Cell Mol Med 23: 5282-5291, 2019.

37. Lang B and Zhao S: MiR-486 functions as a tumor suppressor in esophageal cancer by targeting CDK4/BCAS2. Oncol Rep 39: 71-80, 2018.
38. Tarasewicz E, Hamdan R, Straehla J, Hardy A, Nunez O, Zelivianski S, Dokic D and Jeruss JS: CDK4 inhibition and doxorubicin mediate breast cancer cell apoptosis through Smad3 and survivin. Cancer Biol Ther 15: 1301-1311, 2014.

This work is licensed under a Creative Commons Attribution-NonCommercial-NoDerivatives 4.0 International (CC BY-NC-ND 4.0) License. 